\title{
MÉTODO SIMPLE DE SELECCIÓN PARA LA PRODUCCIÓN DE SEMILLA DE PAPA
}

\author{
EDDY V. ALVAREZ *
}

\begin{abstract}
RESUMEN
Estudios realizados por el Instituto Boliviano de Tecnología Agropecuaria, en zonas paperas del país situadas por encima de los 3.000 metros de altura, confirmaron que la técnica de selección positiva es una alternativa a corto plazo, para suplir la poca disponibilidad de buena semilla de papa, sin alterar las costumbres tradicionales de siembra utilizadas por el pequeño agricultor, como también conservar sus propias variedades nativas. Se consiguió incrementar en $39.25 \%$ el rendimiento promedio de las plantas marcadas correspondientes a las variedades: Sani imilla, Imilla blanca, Manzana, Huaycha paceña, Malcacho y un grupo compuesto por una mezcla de variedades. Cada variedad tuvo diferente respuesta a la técnica de selección positiva, además se establecieron diferencias en cuanto a la facilidad y dificultad en la detección de síntomas de enfermedades. En los diferentes años de estudio, la incidencia de plagas y enfermedades fue variable debido a la influencia de los cambios climatológicos.
\end{abstract}

Palabras Claves Adicionales: cultivar, virus, pestes, climático, nativas.

\section{ABSTRACT \\ Simple Selection Method for Seed Potato Production}

A study was made by Instituto Boliviano de Tecnología Agropecuaria IBTA, to show the concenience of potato seed selection in grower's fields at altitudes over 3.000 meter over sea level. The method utilized traditional practices of farmers as well as their own native cultivars. The cultivars Sani Imilla, Imilla blanca, Manzana, Huaycha paceña and Malcacho showed an average yield increase of 39 percent after using the field selected seeds. Each cultivar had its own virus symptoms expressions, and some were easier to detect by visual selection. The percent of yield increase after selection was also variable according to the cultivar utilized. The presence of pests in the fields during various years depended much on climatic conditions.

Additional Index Words: cultivar, virus, pests, climatic, native.

La papa en Bolivia, además de ser uno de los cultivos de mayor importancia desde los puntos de vista social, económico y agrícola, constituye el alimento básico de las poblaciones urbana y rural,

* Ingeniero Agrónomo, Programa Nacional de Papa IBTA-PRACIPA, Estación Experimental Toralapa, Casilla 2631 Cochabamba-Bolivia. 
particularmente de aquella que habita las zonas altas del país.

La semilla utilizada por el pequeño agricultor no es de buena calidad sanitaria, puesto que proviene de una simple selección con base en su tamaño y forma. Al momento de la selección el agricultor destina para semilla los tubérculos más pequeños, mientras que los grandes son escogidos para su comercialización en los mercados.

Por otra parte, los agricultores tienen preferencia por variedades nativas, de calidad y gusto especial, procedentes de diferentes regiones consideradas tradicionalmente como productoras de buena semilla, aunque sus condiciones de sanidad sean desconocidas. Teniendo en cuenta estos aspectos, en febrero de 1984, con el auspicio del Programa Andino Cooperativo de Investigación en Papa —PRACIPAPA—, se inició el presente trabajo, cuyo objetivo principal estuvo orientado al "Mejoramiento de la Producción de Semilla de Papa de los Pequeños Agricultores" con el empleo de sus propios métodos de siembra y utilizando sus mismas variedades.

En países andinos como Bolivia, Colombia, Ecuador y Perú, el cultivo de la papa usa muchas variedades nativas, y aún no se tiene conciencia del efecto dañino de las enfermedades viróticas, puesto que los productores ponen más atención al nombre de la localidad de donde proviene la semilla que a la calidad sanitaria de ésta $(1,3,7)$.

Hooker (4) y Lecaros (5) indican que la calidad sanitaria de la semilla de papa, es uno de los factores importantes para un buen rendimiento, ya que una vez que la planta ha contraído una enfermedad no hay medio económico y eficaz para controlarla.

Abbot (1), Bryan (2) y Naranjo (6) concuerdan en que un productor de papa, puede producir su propia semilla y obtener una mejor cosecha mediante la selección de las mejores plantas y almacenando su cosecha por separado. La práctica del descarte, puede mejorar la eficiencia de esta técnica, requiriéndose solamente la habilidad del agricultor para reconocer los síntomas de las enfermedades que atacan al cultivo de papa.

\section{MATERIALES Y MÉTODOS}

El presente estudio se efectuó durante los años 1984, 1985 y 1986, para lo cual se tomó en cuenta las principales zonas paperas tradicionalmente consideradas como productoras de semilla, en los departamentos de La Paz, Oruro, Cochabamba, Chuquisaca y Potosí, situados por encima de los 3.000 metros de altura (Figura 1) 


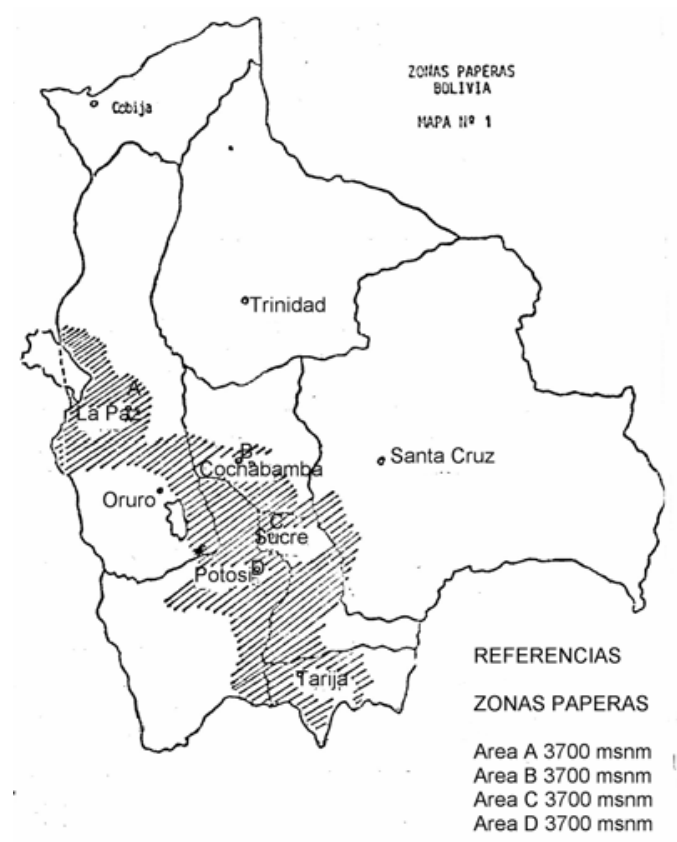

Figura 1.-Zonas paperas de Bolivia.

\section{Selección de Agricultores y Parcelas}

A través de la cooperación de los agentes de extensión agrícola, fueron seleccionados 25 agricultores con base en su predisposición y deseo de cooperar con el estudio.

\section{Selección de Variedades}

En cada una de las áreas y zonas se utilizaron semillas de las variedades nativas más representativas y tradicionalmente cultivadas.

\section{Preparación del Suelo}

La preparación de los terrenos fue ejecutada siguiendo los métodos comúnmente usados por el agricultor, mediante un arado de madera a tracción animal. 


\section{Siembra}

En vista de que todas las parcelas se encuentran en zonas de agricultura a secano y por tanto condicionadas al régimen de lluvias, las siembras se efectuaron entre el 15 de octubre y el 15 de noviembre.

Esta labor fue ejecutada en surcos abiertos y tapados con el mismo arado de madera. Previamente al tapado de surcos, fue distribuido en el fondo de estos, al voleo, fertilizante químico, sólo en unos casos, y simultáneamente con materia orgánica descompuesta en otros. La siembra de tubérculos se hizo entre 30 y $40 \mathrm{~cm}$ sobre el surco y a 70 u $80 \mathrm{~cm}$ entre surcos.

\section{Tamaño y Peso de Tubérculos}

Durante el primer año, se dejó que el agricultor eligiera el tamaño y peso de la semilla. En el segundo y tercer año, se trató en lo posible, de uniformar el tamaño de semilla tanto para las plantas marcadas como para las no marcadas.

\section{Fertilización}

Excepto en el primer año, las parcelas demostrativas recibieron la aplicación de fertilizantes en una proporción de 80-120-0, la misma que recomienda la Estación Experimental Toralapa.

\section{Factores Culturales}

Todas las parcelas recibieron igual atención en cuanto a deshierbes, aporques y tratamientos fitosanitarios, especialmente para el control de insectos vectores de virus.

\section{Marcación de Plantas}

En el período de inicio y plena floración del cultivo, se procedió a la marcación de aquellas plantas aparentemente libres de enfermedades, buena constitución, vigor y pureza varietal. Para el efecto, se utilizaron cintas plásticas de color celeste, con las cuales se marcaron o señalaron 700 plantas en cada lote, totalizando en cada año alrededor de 4.000.

\section{Cosecha}

Al cabo del ciclo vegetativo del cultivo, se procedió a la cosecha individual tanto de las plantas marcadas y no marcadas, cuya producción se pesó por separado. Paralelamente, se tomaron al azar 25 plantas de ambos grupos, cuyo peso también fue registrado. 


\section{RESULTADOS Y DISCUSIÓN}

En la Tabla 1 se muestra el rendimiento y ganancia encontrados en el estudio orientado hacia la aplicación de la selección positiva. Los valores resultantes están conformados por el promedio de 25 plantas marcadas y no marcadas que dio un peso de $0.975 \mathrm{Kg}$ por planta seleccionada y $0.579 \mathrm{Kg}$ por planta no seleccionada, con un incremento para esta técnica de 0.376 Kg por planta y 15 toneladas por hectárea, lo cual corrobora el hecho de que se puede incrementar los rendimientos de los pequeños agricultores como se ha anotado en otros estudios Bryan (2), Naranjo (6), resaltando que estos resultados se obtuvieron sin cambiar las costumbres tradicionales de cultivos y con el empleo de las variedades nativas comúnmente cultivadas.

TABLA 1.- Rendimiento promedio en Kg por planta e incremento obtenido (\%) mediante el método de selección positiva.

\begin{tabular}{llccc}
\hline Variables en estudio & \multicolumn{3}{c}{ años } \\
& 1984 & 1985 & 1986 & Promedio \\
\hline Rendimiento con selección & 0.900 & 0.9387 & 1.028 & 0.975 \\
Rendimiento testigo & 0.506 & 0.6030 & 0.628 & 0.579 \\
Incremento en Kg/planta & 0.394 & 0.3357 & 0.400 & 0.376 \\
Incremento en \% & 43 & 35.76 & 39 & 39.25 \\
Incremento en t/ha* & 15.760 & 13.428 & 16.00 & 15.062 \\
\hline
\end{tabular}

*Considerando un promedio de 40.000 plantas/ha.

El rendimiento promedio y ganancia obtenidos, entre plantas marcadas y no marcadas, para cada una de las variedades en estudio, se aprecia en la Tabla 2, donde se observa una completa

TABLA 2.--Rendimiento e incremento en favor de la narración de plantas en cinco variedades y una mezcla de ellas, durante 1984, 1985 y 1986.

\begin{tabular}{|c|c|c|c|c|}
\hline \multirow[t]{2}{*}{ Variedad } & \multirow{2}{*}{$\begin{array}{c}\text { Peso promedio } \\
\text { Kg. }\end{array}$} & \multirow{2}{*}{$\begin{array}{c}\text { Peso promedio } \\
\text { seleccionadas } \\
\text { Kg. }\end{array}$} & \multicolumn{2}{|c|}{ Incremento } \\
\hline & & & Kg. & $\%$ \\
\hline Sani imilla & 0.9688 & 0.6175 & 0.3513 & 36 \\
\hline Imilla blanca & 0.8783 & 0.4168 & 0.4615 & 52 \\
\hline Huaycha paceña & 1.1713 & 0.555 & 0.6163 & 53 \\
\hline Malcacho & 0.8774 & 0.5977 & 0.2777 & 32 \\
\hline Manzana & 0.8287 & 0.5139 & 0.3138 & 38 \\
\hline Mezcla ** & 1.052 & 0.5426 & 0.5044 & 48 \\
\hline
\end{tabular}


variabilidad de respuesta a la selección positiva. El mayor rendimiento e incremento se logró con la variedad Huaycha paceña, con $1.1713 \mathrm{Kg}$. por planta marcada, cantidad que representa una ganancia de 53\%. Respecto a esta variedad, conviene indicar que a nivel de campo, es posible determinar con claridad y facilidad los síntomas viróticos, lo cual no ocurre con otras variedades, como por ejemplo Malcacho, que es muy asintomática, lo anterior explica probablemente la razón de no haberse encontrado una mayor respuesta a la selección positiva en ella.

La Tabla 3 incluye una lista de las principales enfermedades, plagas y nematodos, presentes en las distintas áreas de trabajo, entre las más importantes, por su incidencia y dificultad de control se encuentran: virus, ojo ciego, Rhyzoctonia solani y Nacobbus spp.

TABLA 3- Presencia de enfermedades, insectos y nematodos en cuatro áreas paperas durante 1984, 1985 y 1986.

\begin{tabular}{|c|c|c|c|c|}
\hline Factores de Estudio & Área A & AreaB & AreaC & AreaD \\
\hline \multicolumn{5}{|l|}{ ENFERMEDADES } \\
\hline Phytophtora infestans de Bary & - & $* *$ & $* *$ & $*$ \\
\hline Synchytrium endobioticum Schil & - & $* *$ & $*$ & - \\
\hline Rhyzoctonia solani Kuhn & $* *$ & $* *$ & $* *$ & $* *$ \\
\hline Spongospora subterranea & $*$ & $*$ & $* * *$ & $*$ \\
\hline Virus & $* * *$ & $* * *$ & $* * *$ & $* * *$ \\
\hline Ojo ciego (sacko) & $* * *$ & $* * *$ & $* * *$ & $* * *$ \\
\hline \multicolumn{5}{|l|}{ INSECTOS } \\
\hline Agrotis spp. & - & - & $* *$ & $* *$ \\
\hline Trips spp. & $*$ & $* *$ & $* *$ & $* *$ \\
\hline Epitrix spp. & $* *$ & $* *$ & $* *$ & $* *$ \\
\hline Phthorimaea operculella & $*$ & $* *$ & $* *$ & $* * *$ \\
\hline Premnotrypes spp. & $* *$ & $*$ & $* *$ & $* *$ \\
\hline \multicolumn{5}{|l|}{ NEMATODOS } \\
\hline Nacobbus spp. & $*$ & $* * *$ & $* * *$ & $* *$ \\
\hline
\end{tabular}

\footnotetext{
: Agente causal no determinado

***: Incidencia alta

**: Incidencia media

*: Incidencia baja

— : Ausencia de síntomas visuales
} 


\section{CONCLUSIONES}

Se ha demostrado cuantitativamente, la eficiencia de la selección positiva en nuestras variedades de origen nativo, y se concluye lo siguiente:

- La simple marcación o selección de plantas (selección positiva) mejora la calidad sanitaria de la semilla de papa del pequeño agricultor, considerando para ello el uso de sus propias variedades nativas.

- Con esta técnica, se pueden incrementar los rendimientos e ingresos de los agricultores en un $39.25 \%$.

- Con el empleo del método de selección, además de una buena fertilización y uso de un tamaño adecuado de semilla, es posible obtener y garantizar buenos rendimientos en zonas de altura, donde el principal problema son las heladas.

- El presente método es una alternativa, a corto plazo, para mejorar los rendimientos del cultivo de la papa de los pequeños agricultores y suplir la poca disponibilidad de semilla.

- Mediante los resultados obtenidos y considerando el promedio nacional de seis toneladas por hectárea, se observa claramente que, hasta ahora, no se está utilizando todo el potencial genético de nuestras variedades, por lo tanto se tendrá que trabajar más desde el punto de vista sanitario.

- Mientras el pequeño agricultor, siga sembrando tubérculos de tamaño reducido (enfermos) y con poca energía germinativa, estará siempre sujeto a perder su cosecha o a tener bajos rendimientos.

- Es necesario efectuar un estudio para determinar, con exactitud, el agente causante del síntoma de la enfermedad llamada ojo ciego o sacko.

\section{REFERENCIAS BIBLIOGRÁFICAS}

1. Abbot. E. V. 1931. Enfermedades de las plantas cultivadas en el Perú. (Boletín de la Dirección de Agricultura y Ganadería año 1).

2. Bryan, J. S. 1980. Técnica de parcelas de semilla de papa a nivel del agricultor. Centro Internacional de la Papa, Lima (Boletín de información Técnica).

3. Eckert, G. 1939. Recomendaciones para mejorar la producción de papa en la sierra. Estación Agrícola La Molina, Lima (Circular $\left.\mathrm{N}^{\circ} 48\right)$.

4. Hooker, W. J. 1980. Compendio de enfermedades de la papa. Centro Internacional de la Papa. Lima, Perú, p. 145-149.

5. Lecaros, J. 1978. Mejoramiento para resistencia a virus. Colloquium de mejoramiento genético, Lima, Perú, 5 p.

6. Naranjo, H. 1986. Cómo manejar su propia semilla de papa. Estación Experimental Santa Catalina, Ecuador (Boletín Divulgativo $\mathrm{N}^{\circ} 191$ ) .

7. Silberschmidt, K. M. 1954. Potato viruse in the America. Phytopatology 44: 415-420. 